\title{
Educación ambiental lúdica para fortalecer habilidades cognitivas en niños escolarizados
}

\section{María Piedad Acuña Agudelo}

https://orcid.org/00oo-0001-7731-5789

Universidad Autónoma de

Bucaramanga, Colombia

macuna@unab.edu.co

\section{Yaneth del Carmen Quiñones Tello}

https://orcid.org/oooo-0001-9920-7324 Universidad Autónoma de Bucaramanga, Colombia yquinones@unab.edu.co

\section{Resumen}

El propósito de esta investigación fue determinar la importancia de la educación ambiental lúdica para el fomento de habilidades cognitivas en niños de 4 a 6 años. La investigación se desarrolló con la estrategia metodológica de la investigación-acción, y enfoque cualitativo. Se revisaron prácticas docentes, se implementaron actividades orientadas al desarrollo de habilidades cognitivas, se analizaron sus efectos, se rediseñaron procesos de la educación ambiental en la primera infancia y se propusieron orientaciones para docentes de educación inicial. El trabajo realizado permitió comprobar que es posible fomentar el desarrollo de estas habilidades cognitivas en los niños escolarizados, utilizando la lúdica como herramienta didáctica y aprovechando el ambiente como el espacio pedagógico.

\section{Palabras claves (Fuente: tesauro de la Unesco)}

Educación ambiental; educación ambiental en la primera infancia; lúdica pedagógica; desarrollo de habilidades cognitivas; prácticas educativas; habilidad; cognición; juego.

Recepción: 21/06/2019 | Envío a pares: 23/10/2019 | Aceptación por pares: 15/07/2020 | Aprobación: 26/08/2020 


\title{
Playful Environmental Education to Sharpen Cognitive Skills in School Children
}

\begin{abstract}
This research intends to determine the importance of playful environmental education for improving cognitive skills in children aged 4-6 years. It was conducted using the action research strategy with a qualitative approach. It reviewed teaching practices, implemented activities aimed at developing cognitive skills and analyzed their effects, redesigned environmental education processes in early childhood, and proposed guidelines for early childhood teachers. Thus, this research proved that it is possible to broaden cognitive skills in school children using play as a didactic tool and leveraging the environment as the pedagogical setting.
\end{abstract}

\section{Keywords (Source: Unesco thesaurus)}

Environmental education; environmental education in early childhood; recreational pedagogy; cognitive skills development; education practices; skills; cognition; play. 


\title{
Educação ambiental lúdica para fortalecer habilidades cognitivas em crianças escolarizadas
}

\author{
Resumo
}

O propósito desta pesquisa foi determinar a importância da educação ambiental lúdica para o fomento de habilidades cognitivas em crianças de 4 a 6 anos. A pesquisa desenvolveu-se dentro da estratégia metodológica da Pesquisa-Ação, com enfoque qualitativo. Revisaram-se práticas docentes; implementaram-se atividades orientadas ao desenvolvimento de habilidades cognitivas e analisaram-se seus efeitos; redesenharam-se processos da educação ambiental na primeira infância; e propuseram-se orientações para docentes de educação inicial. O trabalho realizado permitiu comprovar que é possivel fomentar o desenvolvimento dessas habilidades cognitivas nas crianças escolarizadas, utilizando o lúdico como ferramenta didática e aproveitando o ambiente como o espaço pedagógico.

\section{Palavras-chave (Fonte: tesauro da Unesco)}

Educação ambiental; educação ambiental na primeira infância; lúdico pedagógico; desenvolvimento de habilidades cognitivas; práticas educacionais; habilidade; conhecimento; jogos. 
Entre los 4 y 6 años los niños aprenden a través del juego, la escucha y la observación. Las actividades que realizan le ayudan al cerebro a desarrollar y comprender sus procesos de pensamiento, los cuales son cada vez más complejos. La infancia temprana (Farkas et al., 2006) le genera al niño una serie de necesidades nuevas, pues su mundo social, las personas y contextos con los que interactúa se amplían, así como las exigencias que le plantea el ambiente social. Cuando el niño interactúa con otro, los otros y el mundo, se favorece su crecimiento y desarrollo, y es allí donde las habilidades cognitivas y sociales cobran importancia, pues contribuyen al proceso de adaptación a su entorno, al brindarle estímulos e información acerca de sí mismo y de la realidad que lo rodea.

El estudio de las habilidades cognitivas en la primera infancia se constituye un requisito indispensable para el logro del éxito educativo en los niños. Millá (2006) expresa que es en esos primeros años en donde se adquieren "las destrezas y conocimientos que constituyen la base sobre la que podrán llevar a cabo aprendizajes escolares como la lectura, la escritura y las matemática" (p. 56). Los procesos evolutivos que experimentan los niños en estas edades les permitirán adquirir las habilidades que establecerán el cimiento para la adquisición de nuevos aprendizajes a partir de la interacción con los otros y con su entorno. Las intervenciones en esta etapa, según Farkas et al. (2006), permiten prevenir problemas en el ajuste o trabajarlos de manera pre$\mathrm{COz}$, previniendo las secuelas que ellos generan en la adolescencia y en el desempeño social del adulto.

Los productos de enseñanza que se forjan en la escuela no muestran apropiación de los valores relacionados con el cuidado del entorno. Los maestros limitan las posibilidades del niño al ofrecerle actividades que no le producen expectativas, pues se enfocan en evocar conocimientos y no en provocar nuevos procesos de aprendizaje. Como la información ya está dada y poco se le exige, el niño se acomoda rápidamente al sistema de repetición que se le ofrece, desaprovechando sus capacidades cognitivas y relacionales, que lo tornan dependiente del adulto.

En España, investigaciones realizadas por Millá dan cuenta de cómo

[...] las dificultades tempranas de aprendizaje hacen referencia de manera especifica a aquellas que se dan en el período comprendido entre el nacimiento y los seis años, y que limitan las posibilidades de alcanzar las destrezas y los conocimientos propios de la etapa infantil. Se correlacionan con dificultades ligadas a la cognición, a los procesos de la atención, la percepción y la memoria, a las habilidades lingüisticas de carácter comprensivo y expresivo, y al procesamiento visoespacial. (2006, p. 56)

Este estudio evidencia la relación existente entre las deficiencias en el entrenamiento infantil en su dimensión cognitiva y cómo estas van a afectar directamente las habilidades que intervienen en el aprendizaje, tales como: la percepción, la atención y la memoria, además de tener incidencia en los procesos comunicativos a nivel de comprensión y de expresión.

Por otra parte, en Barranquilla, Campo manifiesta que "cuando el niño tiene edad suficiente (4 a 7 años) para iniciarse en la etapa escolar, su pensamiento se inclina en una mayor medida en la verbalización de sus procesos mentales [...], ahora emplea continuamente el lenguaje verbal" (2009, p. 344). Lo afirmado por Campo refiere que en esta etapa los niños utilizan la expresión oral como canal comunicativo principal a través del cual dan a conocer la evolución en su pensamiento, lo cual impacta su proceso de aprendizaje, por cuanto favorece la comprensión de su entorno y la adaptación a él.

El objetivo general planteado en este proyecto fue determinar la importancia de la educación ambiental y la lúdica para el fomento de habilidades cognitivas en niños de 4 a 6 años en dos jardines infantiles de Bucaramanga. Por su parte, los objeti- 
vos específicos fueron: revisar las prácticas docentes para determinar cuáles se orientan al desarrollo de habilidades cognitivas a través de la educación ambiental y la lúdica; diseñar estrategias para el fomento de estas habilidades a través de la educación ambiental y la lúdica; implementar actividades y analizar los efectos de la implementación de habilidades cognitivas a través de la educación ambiental y la lúdica, que redunda en el diseño de unas orientaciones sobre la enseñanza de la educación ambiental dirigida a docentes de educación inicial.

Entre los autores que mencionan el tema de estudio, se destacan Piaget (2005), Malaguzzi (en Inspirados, s.f.), Elosúa y García (1993), Gopnik (en Revista 21, s.f.), entre otros. Según Piaget:

En los caracteres más generales del comportamiento, con los dos polos de la adaptación: asimilación y acomodación, ¿se encuentran los factores cognitivos y afectivos igualmente disociados? Todo comportamiento es una adaptación, y toda adaptación el restablecimiento del equilibrio entre el organismo y el medio [...]. Pero estas nociones de equilibrio y de desequilibrio tienen un valor cognitivo: asi es como la teoría de la Gestalt define la percepción como una equilibración. La ley de la buena forma es una ley de equilibrio. Las operaciones intelectuales tienden también hacia las formas de equilibrio. La noción de equilibrio tiene pues una significación fundamental, tanto desde el punto de vista afectivo como intelectual. (2005, p. 20)

Es así como para Piaget, en la asimilación conceptual, un objeto es comprendido si es asimilado a los esquemas conceptuales que ya existen en el individuo, es decir, al conjunto de operaciones mentales de las que dispone el sujeto.

Por su parte, Malaguzzi, filósofo ideador de un proyecto educativo que inició en una ciudad del norte de Italia, plantea entre sus principios que "el niño es un ser extraordinario, complejo e individual que existe a través de sus relaciones con los otros y siempre dentro de un contexto particular. Surge como coconstructor, de conocimiento, cultura y de su propia identidad desde el comienzo de su vida. Es entendido y reconocido como un miembro activo de la sociedad" (citado en Inspirados, s.f., p. 1).

En palabras de Malaguzzi (citado en Burshan, 2006), se trata de hacerlo "rico en potencial, fuerte, poderoso y competente":

Un niño que está lleno del deseo y la habilidad de comunicarse desde el inicio de su vida, completamente capaz de crear mapas para la orientación personal, social, cognitiva, afectiva y simbólica. Por todo esto, el niño reacciona en un sistema competente de habilidades, aprendiendo las estrategias y las maneras de organizar las relaciones. (p.4)

No hay, por lo tanto, una niñez ni un niño natural o universal verdaderamente, pero sí existen muchas infancias. Por ello una buena infancia sería aquella en la que el niño es reconocido y promovido. Aquí el niño nace con las capacidades para aprender, no necesita preguntar ni tener el permiso adulto para comenzar a aprender. El aprendizaje es una actividad cooperativa y comunicativa en la cual los niños son agentes activos que construyen el conocimiento, el compromiso y crean significados del mundo, en conjunto con los adultos y, de igual importancia, con otros niños. "Una misión de la institución educativa quizás sea la de proporcionar un foro donde niños y adultos se reúnan para construir juntos conocimiento y cultura" (Malaguzzi, citado en Burshan, 2006).

Con estas afirmaciones, Malaguzzi (citado en Burshan, 2006) da a entender que el niño debe ser reconocido como un actor social, como una persona que puede tomar parte en la construcción y determinación de su vida, de su entorno y de la sociedad, pues, al considerar sus opiniones como importantes $\mathrm{y}$ al hacer reestructuraciones gubernamentales a partir de ellas, se evidencia su competencia cognitiva y su empoderamiento como sujeto de derecho. 
Otros autores que tratan el tema son Elosúa y García (1993), quienes mencionan en sus escritos las estrategias cognitivas para enseñar y aprender a pensar. Estos autores expresan que una estrategia es un plan de acción para lograr un objetivo. Plantean tres tipos de estrategias:

- Estrategias cognitivas: constituyen métodos o procedimientos mentales para adquirir, elaborar, organizar y utilizar información que hacen posible enfrentarse a las exigencias del medio, resolver problemas y tomar decisiones adecuadas.

- Estrategias motivacionales: en el aprendizaje, además de los factores y estrategias cognitivas, están siempre presentes factores motivacionales, que resultan tan importantes como los cognitivos para lograr buenos resultados. En algunas ocasiones el alumnado fracasa en las tareas académicas, no tanto por carecer de estrategias cognitivas, como por un déficit en estrategias motivacionales que le permitan desarrollar y mantener un estado motivacional y un ambiente de aprendizaje apropiado.

- Estrategias metacognitivas: la metacognición, por una parte, hace referencia a los procesos de pensamiento que la persona tiene acerca de su propio sistema cognitivo (contenidos, procesos, capacidades, limitaciones...) y, por otra, a los efectos reguladores que tal conocimiento puede ejercer en su actividad (Elosúa y García, 1993, pp. 3-4).

De las estrategias mencionadas, las cognitivas aportaron elementos para dar una mirada a las habilidades cognitivas trabajadas: atención, percepción y memoria.

Gopnik expresa que "nuevas ideas teóricas e investigaciones empíricas muestran que el aprendizaje y el pensamiento de los niños muy pequeños son similares a gran parte del aprendizaje y el pensamiento en la ciencia" y señala que algunos estudios han demostrado que hay "características del razonamiento de los niños en edad preescolar parecidas a las del razonamiento de los científicos durante sus investigaciones. En concreto, se habla de las relacionadas con el uso de deducciones sobre causas y efectos, hipótesis y comprobaciones" (reseñado en Revista 21, s.f., p. 1).

Las afirmaciones de Gopnik hacen evidente cómo los niños, antes de ser escolarizados, por las interacciones con las personas que los rodean y por la exploración de su entorno desarrollan las habilidades que necesitan para un aprendizaje efectivo y, sin haber sido orientados, utilizan elementos como la observación, comparación, formulación de hipótesis, interpretación y análisis elementos que revelan los procesos cognitivos que vivencian independientemente de su edad cronológica.

Por otra parte, Díaz muestra que el docente requiere utilizar estrategias de diversa índole para enfocar "la atención en las estrategias metacognitivas, ayudar al estudiante a comprender mejor el conocimiento adquirido y [que] además logre un aprendizaje significativo, capaz de aplicarlo en otros campos de su vida" (2016, p. 6). Ello lo invita a planificar su trabajo de manera que, al llevarlo a la práctica, se mejoren los aprendizajes que el estudiante adquiere y pueda posteriormente aplicarlos en diferentes contextos.

Algunos conceptos de relevancia en este proyecto de investigación son:

CoGNICIÓN: la cognición hace énfasis en procesos internos del niño, quien juega un papel activo y responsable en su aprendizaje y va aprendiendo a organizar sus conocimientos. Varela expresa que es el "procesamiento de información: manipulación de símbolos basada en reglas" (1998, p. 43). El término "cognición" es genérico y se refiere a procesos cognitivos específicos como atención, percepción, memoria, pensamiento, razonamiento, etc. (Elosúa y García, 1993, p. 3).

HabILIDADES COGNITIVAS: las habilidades cognitivas son las distintas capacidades intelectuales que de- 
muestran los individuos al hacer algo. Estas habilidades "se comparan con los obreros del conocimiento. Pueden verse afectadas por la índole misma de la tarea a realizar, la actitud del sujeto y determinadas variables de contexto" (Betina et al., 2010, p. 27)

Por su parte, Pueyo define las habilidades cognitivas como

[...] aquellas cualidades o rasgos caracteristicos de una persona que están presentes al momento de realizar una tarea mental y que corresponde al desarrollo-por entrenamiento o práctica-de las capacidades potenciales del individuo. El concepto de habilidades ha sido la piedra angular en el estudio de las medidas de la inteligencia, por lo que Das, Naglieri \& Kirby (1994) citados por Lacunza \& Castro (2010) sostienen que éstas se encuentran organizadas jerárquicamente; dentro de esta jerarquía, existen habilidades generales y especificas, según el contenido de las tareas a ejecutar por el sujeto o por el proceso mental subyacente (1996, citado en Betina et al., 2010, p. 27)

Las habilidades cognitivas las definen Lavado et al. (2015) como la capacidad que tiene un niño o niña para desarrollar estructuras matemáticas, verbales y de comprensión de lectura. En la primera infancia, las habilidades cognitivas están relacionadas con la manera como los niños comprenden y procesan la información, resuelven problemas, establecen comparaciones, interpretan imágenes, asocian letras y sonidos o estímulos visuales.

Procesos cognitivos básicos en los niÑos: las habilidades cognitivas ayudan al niño a comprender el mundo que lo rodea, a procesar la información y a comunicarse. Entre los procesos básicos que los niños desarrollan desde sus primeros años de vida están la percepción, la atención y la memoria.

- La percepción: según Marina, implica "coger información y dar sentido" (1998, citado en Fuenmayor y Villamil, 2008, p. 110). Esto significa que la información no involucra solo el acto de ver, leer, oír, sino también la comprensión e interpretación de relaciones.

- La atención: se da cuando el receptor empieza por captar activamente lo que ve y lo que oye, "y comienza a fijarse en ello o en una parte de ello, en lugar de observar o escuchar simplemente de pasada. Esto se debe a que el individuo puede dividir su atención de modo que pueda hacer más de una cosa al mismo tiempo" (Fuenmayor y Villamil, 2008, p. 193). Para ello adquiere destrezas y desarrolla rutinas automáticas que le permiten realizar una serie de tareas sin prestar, mucha atención.

- La memoria: se entiende como "la capacidad de retener y evocar información de naturaleza perceptual o conceptual" (Viramonte, 2000, p. 31, citado en Fuenmayor y Villamil, 2008). Significa que la memoria es la facultad por medio de la cual se retiene y recuerda el pasado, se almacena el conocimiento que se tiene sobre algo y las interpretaciones que se hacen de ello.

LúdicA: para la Real Academia Española, la palabra lúdica se define como "perteneciente o relativo al juego". Es así como el Ministerio de Educación Nacional (2014a) menciona que

[...] el juego es una de las actividades rectoras de la infancia, junto con el arte, la literatura y la exploración del medio, ya que se trata de actividades que sustentan la acción pedagógica en educación inicial y potencian el desarrollo integral de las niñas y los niños; también deben estar presentes en acciones conjuntas con la familia a través de la valoración e incorporación de su tradición lúdica, representada en juegos, juguetes y rondas. (p. 16)

Como en el proyecto se parte de la educación ambiental y la lúdica para fomentar habilidades cognitivas en niños de 4 a 6 años, se considera fundamental que en estas edades los niños aprendan jugando. 
EDUCACIÓN AMBIENTAL: es importante tener presente que las interacciones que se generan en los niños a partir del contacto con su entorno y con ambientes enriquecidos a través de experiencias pedagógicas fomentan procesos de aprendizaje con un mayor sentido. Malaguzzi plantea que "el niño aprende interaccionando con su ambiente, transformando activamente sus relaciones con el mundo de los adultos, de las cosas, de los acontecimientos y, de manera original, de sus coetáneos. En este sentido participa en la construcción de su yo y en la construcción del yo de los otros" (2001, p. 58, citado en MEN, 2014b, p. 13).

El ambiente se constituye en la primera infancia en el medio de exploración de los niños, por ser el entorno inmediato en donde puede convivir, experimentar, establecer vínculos con los otros y desarrollarse armónicamente.

En la revisión de la literatura relacionada con la temática se presentan investigaciones a nivel internacional y nacional.

A nivel internacional, Santana y Ortega (2010), en Cuba, dan orientaciones sobre educación ambiental para los profesores de formación de la enseñanza media superior. Su finalidad es elevar los conocimientos acerca de la educación ambiental de los profesores en formación de la Enseñanza Media Superior. Plantean la necesidad de promover, formar y desarrollar valores en la personalidad para el comportamiento adecuado con el medio ambiente, lo cual constituye uno de los principales fines de la educación ambiental. Concluyen afirmando que si los maestros y la escuela son capaces de transmitir a las familias las orientaciones planteadas, habrán dado un gran paso en la ulterior comprensión y apropiación de valores, que constituye la base sólida en que descansa la personalidad ambientalmente formada y a favor del desarrollo sostenible. El proyecto aborda las tareas profesionales a desarrollar en el proceso de formación pedagógica del profesional de la educación, los cuatro pilares de la educación que cada docente debe aspirar a alcanzar en sus alumnos y los conceptos fundamentales relacionados con la temática del medio ambiente a los cuales es importante prestar atención.

Betina et al. (2010), en la investigación titulada "Las habilidades cognitivas en niños preescolares. Un estudio comparativo en contexto de pobreza", expresan como finalidad describir las habilidades cognitivas simultáneas y secuenciales de niños en situación de pobreza de San Miguel de Tucumán (Argentina). Las habilidades cognitivas se discriminaron a partir de la Batería de Evaluación de Kaufman para niños (K-ABC). Los análisis estadísticos multivariados mostraron diferencias estadísticamente significativas en el desempeño cognitivo según los niveles de pobreza en los grupos de 4 y 5 años, particularmente en las habilidades secuenciales. Este estudio aporta datos útiles en la planificación de los currículos escolares en el nivel inicial.

En España, Sáiz et al. (2014), en su artículo "Aprendizaje de habilidades de autorregulación en niños de 5 a 7 años", plantearon como objetivos: a) comprobar si la enseñanza de estrategias de autorregulación a niños pequeños con desventaja social mejora sus habilidades de resolución de tareas; $b$ ) evaluar la eficacia de un programa de enseñanza de estrategias de autorregulación, desde la perspectiva del profesorado. Los resultados indicaron que existen mejoras significativas, antes-después de la aplicación del programa, en habilidades: atencionales, de planificación manifiesta guiada y autónoma, de planificación encubierta y de autoevaluación en la resolución de problemas cognitivos y social. Paralelamente, el profesorado consideró que el programa ha mejorado en sus alumnos: los niveles atencionales y la generalización de las estrategias a otras actividades curriculares. Como aporte a la investigación se resalta que las estrategias de autorregulación se constituyen en una herramienta efectiva y motivadora para la docencia en entornos de compensación educativa.

López (2007), en la investigación "La inteligencia social: aportes desde su estudio en niños y adolescentes con altas capacidades cognitivas", con 
el objetivo de estudiar algunos componentes de la inteligencia social en niños y adolescentes con alta capacidad cognitiva (ACC), realizó un estudio cuasiexperimental de tipo ex post facto. La hipótesis de estudio era que los niños y adolescentes con ACC presentarían un rendimiento significativamente superior a sus pares en tareas de razonamiento social. Los resultados indicaron que estos niños y adolescentes presentaron un rendimiento significativamente superior a sus pares en tareas relacionadas con la inteligencia social, destacando sobre todo en procesos de razonamiento que involucraban la comprensión y definición del problema social, la planificación de estrategias y la anticipación de consecuencias sociales.

Por otra parte, la investigación "Desarrollo de las habilidades cognitivas en niños de edad escolar" de Romero y Tapia (2014), realizada en Venezuela, analizó el desarrollo de las habilidades cognitivas en niños de Educación Primaria, abordando dos dimensiones: fases de adquisición y procesos del pensamiento. En una investigación descriptiva, de campo, no experimental, la población de estudio estuvo constituida por 86 niños de edad escolar; la técnica de recolección de datos utilizada fue la encuesta y el instrumento, una prueba de conocimiento; los datos se procesaron con estadística descriptiva. Los autores demuestran que las fases de adquisición de las habilidades cognitivas en los escolares se encuentran consolidadas, así como los procesos del pensamiento: observación, comparación, análisis y sintesis; sin embargo, en la descripción y relación se evidenció que aún están en proceso de consolidación. Como aporte a la presente investigación, el trabajo fortalece el desarrollo de las habilidades cognitivas ya consolidadas en los primeros años y aborda procesos del pensamiento.

En Ecuador, Gámez (2019), en la tesis de maestría "Implementación de estrategias metacognitivas, para un aprendizaje significativo en el nivel inicial", planteó como objetivo diseñar una propuesta educativa que permitiera el desarrollo de la metacognición en los estudiantes de educación inicial de una unidad educativa fiscal del cantón Esmeraldas. Utilizó una metodología constructivista en donde es el niño es el que construye su propio aprendizaje. Entre las conclusiones, la autora plantea que los procesos metacognitivos deben ser aplicados desde el nivel inicial y continuar su aplicación implementación y uso hasta la universidad. Para lograrlo, es indispensable el papel de los profesores, como facilitadores de las herramientas y materiales necesarios. El aporte plantea que una selección adecuada de las habilidades cognitivas conduce a un aprendizaje significativo.

A nivel nacional, Montoya et al. (2012) publicaron la investigación "Correlation between the reading and writing academic skills and the neuropsychological performance in a sample of children with adhd from the city of Manizales", que buscó correlacionar el desempeño neuropsicológico con las tareas de habilidades académicas de lectura y escritura, cruzando las variables correspondientes a estas habilidades contra el proceso de atención, memoria y el desempeño en funciones ejecutivas. Se confirmó el valor predictivo que tiene el desempeño de los niños y niñas en la evaluación de algunas variables neuropsicológicas, en sus posibilidades de funcionamiento escolar y en su nivel de apropiación y desempeño académico. El aporte corresponde al avance hacia el estudio de las habilidades académicas en los niños.

La investigación "El desarrollo de las habilidades cognitivas a través de la enseñanza de las plásticas y visuales", realizada en la Universidad Santo Tomás de Bogotá, plantea que "las artes plásticas estimulan la conexión entre diversas partes del cerebro, lo cual potencia las capacidades de aprendizaje. Por tanto, la educación artística en la formación escolar no debería ser un lujo, ni una opción prescindible o una parodia para llenar el horario" (Figueroa, 2015, p. 11).

A pesar de que en los procesos artísticos se desarrollan las competencias en pensamiento estético, creatividad, expresión y sensibilidad artística, 
en las instituciones educativas no se ha otorgado la importancia que esta tiene en la formación integral del estudiante. El propósito central fue identificar las estrategias didácticas empleadas por los docentes de artes plásticas y visuales de educación básica primaria para el desarrollo cognitivo de los niños y niñas. Entre las conclusiones, el autor destaca que, a pesar de que los maestros consideran que los niños y niñas sí alcanzan el desarrollo cognitivo a través de las artes plásticas y visuales, aún no comprenden que el desarrollo de habilidades artísticas está estrechamente unido al desarrollo intelectual del niño. Como aporte a la presente investigación, se destaca la afirmación del autor de que los docentes no contemplan en su planeación curricular estrategias didácticas en artes plásticas y visuales que contribuyan al desarrollo cognitivo de los niños y niñas, pero cuentan con una serie de actividades mediante las cuales se llevan a cabo los procesos pedagógicos. Se evidencia que aún falta preparación en didáctica, para así sacar provecho de las bondades de la enseñanza de las asignaturas mencionadas.

A nivel local, el trabajo "Experimentos científicos infantiles como medios para generar actitudes y aptitudes investigativas en los niños de 5 años del grado transición del colegio Liceo Pedagógico La Dicha del Saber de la ciudad de Bucaramanga" (Sierra, 2017), en su problemática plantea reconocer algunos aspectos de la realidad escolar con relación a las actitudes y aptitudes investigativas que tienen los niños de educación preescolar. Para ello, la autora se pregunta qué actitudes y aptitudes investigativas se generan en los niños de 5 años del grado de transición. El propósito general fue generar actitudes y aptitudes investigativas en los niños de 5 años del grado transición, mediante acciones pedagógicas en torno a experimentos científicos infantiles. Como aporte al presente proyecto, se encontró la misma metodología de trabajo: la investigación-acción (IA), además que en el proyecto la autora logra demostrar que los experimentos científicos infantiles son una estrategia pedagógica favorable al desarrollo de las actitudes y aptitudes investigativas infantiles.

\section{Metodología}

En el proyecto se trabajó a partir de la investigación-acción, por constituir una "fórmula diferente de las concepciones tradicionales de la investigación educativa, y sus relaciones con otras formas de reflexión sobre la práctica" y porque se relaciona con los problemas prácticos cotidianos experimentados por los profesores, en vez de con los "problemas teóricos" definidos por los investigadores puros en el entorno de una disciplina del saber (Elliot, 200o, pp. 4-5). Por su parte, Lewin la define como "una forma de cuestionamiento autorreflexivo, llevada a cabo por los propios participantes en determinadas ocasiones con la finalidad de mejorar la racionalidad y la justicia de situaciones, de la propia práctica social educativa, con el objetivo también de mejorar el conocimiento de dicha práctica y sobre las situaciones en las que la acción se lleva a cabo" (1946, p. 3).

Para este autor, la investigación-acción sigue un modelo en espiral en el cual se realizan las siguientes fases:

- $\quad$ Problematización. Se parte de un problema práctico, se determinan sus características y las diferentes perspectivas, y se ordenan, agrupan y relacionan los datos de acuerdo con los objetivos de la investigación, con el fin de proceder a su análisis.

- Diagnóstico. Consiste en recoger evidencias, notificar sobre las acciones que se han desarrollado, expresar el punto de vista de las personas implicadas e informar cómo las personas implicadas viven y entienden la situación que se investiga.

- Diseño de la propuesta de cambio. Se consideran las diversas alternativas de actuación y sus posibles consecuencias. Una reflexión continua permite diseñar una propuesta de cambio y mejoramiento y definir un diseño de evaluación de la misma.

- $\quad$ Aplicación de la propuesta. Se lleva a cabo la propuesta, lo cual implica nuevas formas de 
actuar, esfuerzos de innovación y mejoramiento de la práctica, que debe ser sometida permanentemente a condiciones de análisis, evaluación y reflexión.

- Evaluación. Se realiza de forma continua durante el proceso de la investigación, pues pueden surgir cambios que requieran una redefinición del problema, de manera tal que las nuevas situaciones y sus consecuencias determinen el proceso de investigación y el probable inicio de otro ciclo en la espiral de la investigaciónacción (Lewin, 1946, p. 20).

En este sentido, la investigación-acción tiene un doble propósito: desde la acción, al tratar de cambiar las prácticas en los jardines en estudio y, desde la investigación, el objetivo de generar conocimiento y compresión, en este caso, de la educación ambiental, para fomentar las habilidades cognitivas en los niños.

La investigación en curso tiene un enfoque cualitativo, donde el investigador plantea un problema, pero no sigue un proceso claramente definido (Hernández, Fernández et al., 2010). Entre sus características están:

- El enfoque cualitativo utiliza la recolección de datos sin medición numérica para descubrir o afinar preguntas de investigación en el proceso de interpretación. Se utiliza primero para descubrir y refinar preguntas de investigación (Grinnell, 1997, citado en Hernández et al., 2010).

- En la búsqueda cualitativa, en lugar de iniciar con una teoría particular y luego "voltear" al mundo empírico para confirmar si ella está apoyada por los hechos, el investigador comienza examinando el mundo social y en este proceso desarrolla una teoría coherente con lo que observa que ocurre. Dicho de otra forma, las investigaciones cualitativas se fundamentan más en un proceso inductivo (explorar y describir y luego generar perspectivas teóricas). Es decir, procede caso por caso, dato por dato, hasta llegar a una perspectiva más general (Grinnell, 1997, citado en Hernández et al., 2010, p. 8).

La población estuvo constituida por niños de dos jardines infantiles en los niveles Jardín y Transición, en edades comprendidas entre 4 y 6 años. A su vez, la muestra estuvo conformada por 25 niños del grado Jardín y 25 niños del grado Transición. Los instrumentos de recolección de información fueron la observación, el diario pedagógico y una entrevista que se realizó a docentes de jardines infantiles.

\section{Resultados y análisis}

Los resultados se presentan a partir de cada uno de los objetivos específicos planteados. El objetivo específico 1 se relacionó con revisar las prácticas docentes para determinar cuáles se orientan al desarrollo de habilidades cognitivas a través de la educación ambiental y la lúdica en niños de 4-6 años. Para ello se realizó encuesta a 36 docentes de preescolar, con el fin de recoger información relevante sobre las habilidades cognitivas y la educación ambiental que manejan docentes de diferentes jardines infantiles de la ciudad; de ellos, en el sector público participaron 14 docentes, en el sector privado 15 y no respondieron 7. La mayoría de los encuestados laboran en los niveles de jardín y transición; y aunque 27 expresaron que durante su formación como docentes han recibido información teórica sobre educación ambiental, 16 de ellos consideran que la información que poseen sobre el tema está reflejada en términos de muy buena, buena o suficiente y 17 de ellos considera que es regular. Al indagar si han recibido información sobre habilidades cognitivas a través de la educación ambiental y la lúdica, 17 docentes respondieron Sí y 19 respondieron NO.

En relación con las habilidades cognitivas que han trabajado con los niños de preescolar, los docentes informaron lo siguiente: atención $=33$, percep- 
ción $=33$, memoria $=27$ y ninguna $/$ no responde $=2$. Así mismo, 10 expresaron que todas las habilidades se trabajan en sintonía e integradas y son importantes, permanentes, paralelas, como dispositivos básicos de aprendizaje. En particular, respecto de cada habilidad expresaron que es importante en el trabajo con los niños. En cuanto a la percepción, para ellos es fundamental porque:

- $\quad$ Predispone los sentidos al aprendizajey, en esa medida y según la riqueza de los estímulos, se alcanzaría la atención y la memoria, no solo en lo cognitivo sino en lo sensorial.

- Reciben información a través de todos los sentidos.

- Les permite estar en contacto con el ambiente que los rodea.

- Los estudiantes suelen ponerle atención y memorizar aquello que perciben como agradable y ven que les interesa, y atienden de la manera como perciben.

En cuanto a la atención, es importante en el trabajo con los niños porque:

- $\quad$ Si el niño logra concentrarse y atender, puede recibir el mensaje apropiadamente y llevarlo a la memoria.

- $\quad$ Permite centrarse y culminar las tareas.

- $\quad$ Sin ella no se pueden desarrollar las demás; es la principal.

- $\quad$ Es muy importante que los niños centren su atención en este tema, ya que de ahí parte el aprendizaje significativo.

En cuanto a la memoria, es importante en el trabajo con los niños porque:

- Incluye haber dominado la atención y percepción.

- No todos tienen la habilidad para recordar fácilmente las cosas vistas.
Al preguntar por las prácticas docentes que han realizado orientadas al desarrollo de habilidades cognitivas a través de la educación ambiental y la lúdica, las que obtuvieron mayor puntaje, ordenadas de mayor a menor, como se observa en la Tabla 1, fueron:

Tabla 1. Prácticas orientadas al desarrollo de habilidades cognitivas a través de la educación ambiental y la lúdica

\begin{tabular}{|l|c|}
\hline \multicolumn{1}{|c|}{ Prácticas } & Encuestados \\
\hline $\begin{array}{l}\text { Cuidado del ambiente: plantas, } \\
\text { animales, mascotas, agua, siembra y } \\
\text { cuidado de las plantas, cuidado del } \\
\text { cuerpo, observación de videos, cómo } \\
\text { vivir en un ambiente sano. }\end{array}$ & 26 \\
\hline $\begin{array}{l}\text { Proyectos de aula y diseño de } \\
\text { ambientes de aprendizaje sobre } \\
\text { el reciclaje y su utilidad, residuos, } \\
\text { clasificación, uso inteligente de los } \\
\text { residuos plásticos, reflexión sobre la } \\
\text { destrucción del medio ambiente. }\end{array}$ & \\
\hline $\begin{array}{l}\text { Actividades lúdicas con material } \\
\text { reciclable, recolectar hojarasca y a } \\
\text { partir de ello crear diferentes cosas, } \\
\text { juegos, juego de roles, coordinación } \\
\text { dramatriz, concéntrese, los sentimientos, }\end{array}$ & 13 \\
\hline
\end{tabular}

Fuente: elaboración propia.

La mayoría de las docentes encuestadas mencionaron trabajar temas relacionados con cuidado del ambiente: de las plantas, los animales y mascotas, el agua, siembra y cuidado de las plantas, el cuidado del cuerpo, la observación de videos, y cómo vivir en un ambiente sano. Otra práctica destacada por un grupo numeroso de docentes encuestados fue el trabajo por proyectos de aula y el diseño de 
ambientes de aprendizaje sobre el reciclaje y su utilidad, los residuos, su clasificación, el uso inteligente de los residuos plásticos, y también realizan diálogos con los niños sobre la destrucción del medio ambiente y sus consecuencias.
Al preguntar por las estrategias que emplean los docentes con mayor frecuencia para desarrollar conciencia ambiental en los niños, en síntesis y ordenándolas desde el mayor puntaje al menor, como se observa en la Tabla 2, estas fueron:

Tabla 2. Estrategias más empleadas por los docentes

\begin{tabular}{|c|c|c|c|c|c|c|c|c|}
\hline \multirow{2}{*}{ Estrategias } & \multicolumn{8}{|c|}{ Puntajes } \\
\hline & 8 & 7 & 6 & 5 & 4 & 3 & 2 & 1 \\
\hline Proyectos del aula centrados en el medio ambiente y su cuidado & 2 & 5 & 4 & 1 & 2 & 6 & 3 & 10 \\
\hline Cuidado de los recursos: agua-luz & - & 6 & 4 & 4 & 2 & 1 & 9 & 7 \\
\hline Reciclaje & 1 & 5 & 2 & 4 & 3 & 5 & 3 & 9 \\
\hline Salidas al parque o ambientes naturales & 4 & 7 & 2 & 3 & 3 & 2 & 3 & 6 \\
\hline $\begin{array}{l}\text { Narración de cuentos con contenido en relación con el medio } \\
\text { ambiente }\end{array}$ & 2 & 2 & 3 & 7 & 3 & 4 & 5 & 7 \\
\hline Actividades lúdicas & - & 2 & 5 & 5 & 4 & 2 & 7 & 9 \\
\hline Campaña con la comunidad para cuidar el medio ambiente & 1 & 4 & 6 & 3 & 5 & 3 & 4 & 6 \\
\hline $\begin{array}{l}\text { Regar y sembrar plantas. Fichas de aplicación con contenidos en } \\
\text { relación con el medio ambiente }\end{array}$ & 1 & 3 & 5 & 4 & 3 & 3 & 6 & 5 \\
\hline
\end{tabular}

Fuente: elaboración propia.

Como otras estrategias, mencionan la indagación en el ámbito familiar sobre las prácticas de reutilización y reciclaje que realizan, información sobre experimentos para trabajar con los niños y el cuidado y compromiso con las mascotas.

Finalmente, al preguntar a los docentes por temas en los cuales les gustaría recibir capacitación, consideraron los siguientes:

- Información teórica sobre educación y conciencia ambientales.

- Estrategias lúdicas para trabajar la conciencia ambiental con niños de nivel inicial.

- Información sobre habilidades cognitivas.

- Cómo incentivar la preocupación de la comunidad educativa hacia el medio ambiente.
- $\quad$ Proyectos educativos de educación y conciencia ambiental.

- Estrategias para evaluar resultados de las acciones educativas ambientales.

A partir del segundo objetivo específico: diseñar estrategias para el fomento de habilidades cognitivas a través de la educación ambiental y la lúdica, se procedió a diseñar y elaborar las planeaciones de actividades relacionadas con las habilidades percepción, atención y memoria. Las planeaciones elaboradas para cada habilidad cognitiva contienen respectivamente: el tema, la competencia, el descriptor de desempeño, las actividades, los recursos y el tiempo, como se observa en la Tabla 3. 
Tabla 3. Algunos ejemplos de actividades relacionadas con la percepción, atención y memoria

\begin{tabular}{|c|c|c|c|c|}
\hline \multirow{2}{*}{$\begin{array}{l}\text { Estrategia } \\
\text { lúdica }\end{array}$} & \multirow{2}{*}{ En qué consistió la actividad } & \multirow{2}{*}{ Evidencia } & \multicolumn{2}{|c|}{ Efectividad } \\
\hline & & & Si & No \\
\hline $\begin{array}{l}\text { Armando } \\
\text { rompecabezas } \\
\text { en equipo }\end{array}$ & $\begin{array}{l}\text { Juego de armar rompecabezas en } \\
\text { equipo para analizar imágenes sobre } \\
\text { la profesión del odontólogo. }\end{array}$ & & $v$ & \\
\hline Mi mural & $\begin{array}{l}\text { Se requería poner a prueba el trabajo } \\
\text { en equipo y ubicar los animales } \\
\text { salvajes y domésticos donde } \\
\text { corresponde creando así un mural. }\end{array}$ & & $v$ & \\
\hline $\begin{array}{l}\text { Juego de roles: } \\
\text { el tendero }\end{array}$ & $\begin{array}{l}\text { La maestra colocó en el suelo } \\
\text { imágenes boca abajo de algunos } \\
\text { elementos comestibles que se } \\
\text { encuentran en los supermercados, } \\
\text { y se prosiguió a jugar a buscar las } \\
\text { parejas, un juego de concentración. }\end{array}$ & & $\begin{array}{l}\text { Al } \\
\text { imágen } \\
\text { querían } \\
\text { yalgur } \\
\text { porqu }\end{array}$ & $\begin{array}{l}\text { las } \\
\text { las niñas } \\
\text { nombres } \\
\text { lestaron } \\
\text { lejaban }\end{array}$ \\
\hline
\end{tabular}

Fuente: elaboración propia.

A partir del tercer objetivo específico: "Implementar actividades orientadas al desarrollo de habilidades cognitivas a través de la educación ambiental y la lúdica en niños de 4-6 años", se realizaron 104 actividades relacionadas con las siguientes habilidades cognitivas: 21 con la habilidad cognitiva de atención, 50 con la percepción, 18 con la memoria, 8 que implicaban las tres habilidades y 7 con solo dos de ellas: percepción y memoria. En todos los casos se presenta la estrategia, en qué consistió la actividad y su efectividad.

A partir del cuarto objetivo específico: "Analizar los efectos de la implementación de habilidades cognitivas a través de la educación ambiental y la lúdica que redundará en el diseño de unas orientaciones sobre la enseñanza de la educación ambiental dirigida a docentes de educación inicial", en la Tabla 4 se presenta el análisis realizado a algunas de ellas. 
Tabla 4. Análisis de los efectos de la implementación de las habilidades cognitivas de atención, percepción y memoria

\begin{tabular}{|c|c|c|}
\hline Actividad & Estrategia & Habilidad cognitiva: atención \\
\hline $\begin{array}{l}\text { 1. Juego de roles: el policía } \\
\text { ambiental }\end{array}$ & $\begin{array}{l}\text { Con la participación de un policía ambiental } \\
\text { observaron un primer video que trataba sobre } \\
\text { los animales que estaban en vía de extinción } \\
\text { y un segundo video sobre cómo cuidar el } \\
\text { medio ambiente: "Humus consumus - humus } \\
\text { responsable" y "Pocoyó y la basura". }\end{array}$ & \multirow{6}{*}{$\begin{array}{l}\text { Los niños reproducen lo vivido a través de } \\
\text { las observaciones del entorno en el cual se } \\
\text { encuentran inmersos. El desarrollo cognoscitivo } \\
\text { se da en el momento en que incorporan el } \\
\text { producto de sus interacciones sociales. Expresan } \\
\text { una manifestación de los elementos del contexto } \\
\text { interiorizados. } \\
\text { En el momento de prestar atención los niños } \\
\text { tienen la capacidad de discriminar qué } \\
\text { información procesar. "La atención es un proceso } \\
\text { básico con el que se inicia el procesamiento de la } \\
\text { información y pone en marcha a otros procesos } \\
\text { cognitivos, regula y ejerce un control sobre la } \\
\text { percepción y la memoria" (García, 1997; Rosselló, } \\
\text { 1998; Ruiz-Vargas, 1982, citados en Tortolero, s.f.). } \\
\text { Reategui (1999) señala que "la atención es un } \\
\text { proceso discriminativo y complejo que acompaña } \\
\text { todo el procesamiento cognitivo; además es el } \\
\text { responsable de filtrar información e ir asignando } \\
\text { los recursos para permitir la adaptación interna } \\
\text { del organismo en relación a las demandas } \\
\text { externas". } \\
\text { Así, la motivación y la emoción son considerados } \\
\text { como factores determinantes de la atención; } \\
\text { de este modo; un estado de alta motivación e } \\
\text { interés estrecha el foco atencional, y disminuye } \\
\text { la capacidad de atención dividida, así como el } \\
\text { tono afectivo de los estímulos que se reciben } \\
\text { y los sentimientos hacia ellos contribuyen a } \\
\text { determinar cuál va a ser el foco de atención } \\
\text { prioritario (García, 1997). }\end{array}$} \\
\hline 2. Juego de roles: el tendero & $\begin{array}{l}\text { Lectura del cuento "Ramón va al supermercado", } \\
\text { observación de imágenes para identificar el rol } \\
\text { del tendero. }\end{array}$ & \\
\hline $\begin{array}{l}\text { 3. Presentación del personaje } \\
\text { de la semana: "el granjero" }\end{array}$ & $\begin{array}{l}\text { Se dio a conocer a los niños el personaje de la } \\
\text { semana, adivinando quién era por medio de } \\
\text { objetos usados por él que se les iban mostrando. }\end{array}$ & \\
\hline 4. El veterinario & $\begin{array}{l}\text { Inicia con el disfraz del veterinario y se realizan } \\
\text { diferentes preguntas a los niños acerca de } \\
\text { la profesión, se les entrega una imagen por } \\
\text { parejas y con sus propias palabras explican cada } \\
\text { situación observada. }\end{array}$ & \\
\hline 5. El veterinario - parte 2 & $\begin{array}{l}\text { A partir de la canción "Mi tío Mario veterinario", } \\
\text { se hacen preguntas, luego a los niños se les } \\
\text { entrega una ficha, con la cual van a crear una } \\
\text { historia a partir de las imágenes que esta } \\
\text { contiene; luego se realizan preguntas acerca de } \\
\text { la historia creada por ellos. }\end{array}$ & \\
\hline $\begin{array}{l}\text { 6. Juego de roles en el metro } \\
\text { línea }\end{array}$ & $\begin{array}{l}\text { Se realiza un juego de roles que represente la } \\
\text { cotidianidad en una estación de metro línea, } \\
\text { explicando cómo deben interactuar en sus } \\
\text { diálogos con otras personas (se resaltan los } \\
\text { comportamientos adecuados en el contexto). }\end{array}$ & \\
\hline Actividad & Estrategia & Habilidad cognitiva: percepción \\
\hline $\begin{array}{l}\text { 1. La planta en 3D. ¿Qué } \\
\text { necesita la planta para } \\
\text { vivir? }\end{array}$ & $\begin{array}{l}\text { Realidad aumentada. Se proyectó en 3D el } \\
\text { dibujo de la planta coloreada por cada niño a } \\
\text { partir de una plantilla dada. Cada niño observó } \\
\text { y seleccionó en la App los tres componentes } \\
\text { principales con que proteger la plantica para } \\
\text { que creciera: cuidado, sol, abono; no siempre } \\
\text { salían las mismas opciones, como agua, podar, } \\
\text { insecticida (opción que no reconocían). }\end{array}$ & $\begin{array}{l}\text { La percepción es una experiencia sensorial } \\
\text { consciente, al tener la oportunidad de comparar } \\
\text { una planta real usando conocimientos previos } \\
\text { y el efecto que se produce en una planta } \\
\text { transformada por la realidad aumentada, con } \\
\text { lo cual obtienen un punto de referencia para } \\
\text { determinar ficción-realidad y constatar sus } \\
\text { presaberes. }\end{array}$ \\
\hline $\begin{array}{l}\text { 2. Comprender el mundo } \\
\text { físico natural }\end{array}$ & $\begin{array}{l}\text { Demostrar curiosidad por comprender los } \\
\text { mundos físico, natural y social, a través de la } \\
\text { observación, la exploración, la comparación, la } \\
\text { confrontacion y la reflexión. Crear una masa } \\
\text { artística con la que podrá realizar diferentes } \\
\text { figuras y moldearlas a su gusto, de acuerdo con } \\
\text { su imaginacion. }\end{array}$ & $\begin{array}{l}\text { Al involucrar varios sentidos, hay diferentes } \\
\text { canales que permiten la percepción de los } \\
\text { estímulos ambientales, lo cual potencia la } \\
\text { interpretación de los estímulos percibidos. }\end{array}$ \\
\hline $\begin{array}{l}\text { 3. Sellos creativos con } \\
\text { material reciclado }\end{array}$ & $\begin{array}{l}\text { Estampando creatividad. Los niños elaboraron } \\
\text { con material reciclado sellos y plasmaron su } \\
\text { creatividad a partir del diseño de figuras y el uso } \\
\text { de pintura. }\end{array}$ & $\begin{array}{l}\text { La creatividad y la expresión artística en el aula } \\
\text { son necesarias para conocer el pensamiento } \\
\text { infantil, dado que esta forma de expresión les } \\
\text { permite comunicarse sin límites y de manera más } \\
\text { espontánea para demostrar su percepción del } \\
\text { mundo que los rodea. }\end{array}$ \\
\hline
\end{tabular}


Actividad

Estrategia

Ayudar a un mono de trapo a construir su historia. Se realizaron diferentes preguntas sobre el cuento. Se solicitó inventar una historia empezando con la frase "Había una vez un mono llamado Snoopy..." y se fue entregando el mono a cada niño para que se familiarizara con él, lo tocara y lo observara.

La actividad consistió en escuchar un cuento. 2. Secuencia de un cuento narrado y adivinanzas
Mencionar la secuencia de pasos que se debe cumplir para elaborar un producto comestible y descifrar adivinanzas.
3. Narración: "Por cuatro esquinitas de nada"
A partir de la narración del cuento "Por cuatro esquinitas de nada", se realizó una reflexión acerca de los valores y respeto por los demás para una sana convivencia.

\section{Habilidad cognitiva: memoria}

El cuento se constituye en un recurso importante como estrategia para acercar a los niños al conocimiento natural.

Permite verificar la comprensión del tema y su capacidad de memorizar lo escuchado: "Analizar la historia de un cuento puede incentivar a los niños a crear una conexión entre sus experiencias personales y las de los personajes. Al identificarse con los personajes del cuento los niños reconocen que no son los únicos que experimentan estos sentimientos o problemas. A través de los temas, personajes e historias presentados en la literatura infantil, los niños pueden aprender estrategias y destrezas que les permitan ser más eficientes e independientes al resolver conflictos" (Carlson, 2001, citado en Castillo, (2013, p. 17). Al respecto el MEN (2014C) expresa que "saber que todo ser humano se nutre de palabras y símbolos y que inventa su historia en esa conversación permanente con las historias de los demás confiere al lenguaje un papel fundamental en la configuración del ser humano. Desde este punto de vista, el lenguaje, en el sentido amplio de capacidad de comunicación y simbolización, la lengua-oral y escrita" (p. 40)

El uso de la memoria visual y auditiva se evidencia cuando la docente presenta el video en donde se aprecian una serie de animales que van apareciendo en forma consecutiva; los niños memorizan el orden y el verso que van entonando mientras van cantando e indicando el nombre del animal que continúa.
4. Música y juego dramático (animales)
Juego dramático acompañado de la canción "La rana cantaba".

Fuente: elaboración propia.

\section{Las tres habilidades: atención, percepción y memoria}

Tabla 5. Análisis de actividades que incluyeron las tres habilidades cognitivas

\begin{tabular}{|l|l|l|}
\hline \multicolumn{1}{|c|}{ Actividad } & \multicolumn{1}{|c|}{ Estrategia } & \multicolumn{1}{c|}{ Habilidad cognitiva } \\
\hline 1. Soy un animal & \multicolumn{1}{|c|}{$\begin{array}{l}\text { La actividad consistió en identificar } \\
\text { las semejanzas de los humanos con los } \\
\text { animales en acciones comunes, tales } \\
\text { como comer, reír, mirar, caer, mediante } \\
\text { un cuento llamado "Soy un animal" } \\
\text { y después identificar los sonidos de } \\
\text { algunos animales. }\end{array}$} & $\begin{array}{l}\text { La literatura infantil ayuda a que la imaginación de los } \\
\text { niños fluya con más creatividad. Y ya que no es fácil } \\
\text { darles vida a unos personajes, con ayuda de los cuentos } \\
\text { e historias esto se hace menos complicado y son más } \\
\text { comprensibles para los niños todos los temas que se } \\
\text { quieran trabajar, dejando que la imaginación tome } \\
\text { un lugar en todo momento, llevando a un espacio de } \\
\text { comprensión y felicidad, expresando lo que aprendieron o } \\
\text { lo que desean a los demás, permitiéndoles comprender el } \\
\text { mundo que los rodea y los retos que les esperan. }\end{array}$ \\
\hline \multirow{5}{*}{$\begin{array}{l}\text { 2. Construyamos un texto } \\
\text { narrativo }\end{array}$} & $\begin{array}{l}\text { "Construyamos un texto narrativo": } \\
\text { dibujar en cinco círculos e inventar un } \\
\text { cuento utilizando: objeto, animal, fruta, } \\
\text { color. En este proceso intervienen la } \\
\text { atención, la percepción y la memoria. }\end{array}$ & \\
\hline
\end{tabular}

Fuente: elaboración propia. 


\section{Dos habilidades: percepción y memoria}

Tabla 6. Análisis de actividades que incluyeron dos habilidades cognitivas

\begin{tabular}{cl}
\multicolumn{1}{c}{ Actividad } & \multicolumn{1}{c}{ Estrategia } \\
\hline 1. Construyamos una casa dio libertad a los niños para hacer una \\
$\begin{array}{l}\text { casa con material reciclable, compararla } \\
\text { con otras y determinar sus semejanzas y } \\
\text { diferencias, como ellos quisieran, de acuerdo } \\
\text { con unas pautas y sus presaberes. }\end{array}$
\end{tabular}

La percepción se evidencia a partir de la observación, selección y comparación de los materiales de los que disponen para realizar su construcción propia Portellano y García (2014) afirman que "La memoria a largo plazo está formada por dos sistemas, la memoria declarativa o explícita y la memoria no declarativa o implícita. A su vez, dentro de estos dos sistemas tenemos otros tipos de memoria.

2. Jugando con material reciclado
Los niños expresaron su creatividad a partir de material reciclado para solucionar un problema que se presentó en un cuento inventado por ellos mismos.
La memoria declarativa almacena y recupera la información de manera consciente y deliberada. Se refiere a las experiencias, hechos y acontecimientos que se adquieren por el aprendizaje. Es la denominada memoria de 'saber qué'”.

\footnotetext{
Se inició la actividad preguntando a los niños qué creían que había entre una maleta. Se fue sacando una taza con las frutas y la venda de los ojos. Se vendaron los ojos de los niños con la venda de colores. El juego consistía en oler una fruta con sus ojos cerrados y adivinar su nombre; algunos debían tocarlas y saborearlas para poder adivinar. No reconocieron la feijoa ni la ciruela. Todos probaron todas las frutas. Después de adivinar la fruta debían escribir su nombre
} 3. ¡Adivina qué fruta es! El inicio de la actividad generó la formulación de hipótesis respecto a lo que encontrarían en la maleta que fue llevada al aula, luego se estimuló la percepción háptica, olfativa y gustativa mediante la manipulación y degustación de las frutas que les eran entregadas. La memoria se evidenció a partir de la situación en donde debían evocar los recuerdos que tenían sobre las frutas y sus olores; quienes no pudieron lograrlo de esta forma se les permitió usar la memoria gustativa.

Fuente: elaboración propia.

\section{Resultados/productos esperados y potenciales beneficiarios}

Resultados relacionados con la generación de conocimiento:

Tabla 7. Generación de nuevo conocimiento

\begin{tabular}{|l|l|l|l|}
\hline \multicolumn{1}{|c|}{ Objetivo de la propuesta } & Resultado/Producto esperado & \multicolumn{1}{c|}{ Indicador } & \multicolumn{1}{c|}{ Beneficiario } \\
\hline $\begin{array}{l}\text { Analizar los efectos de la } \\
\text { implementación de habilidades } \\
\text { cognitivas a través de la } \\
\text { educación ambiental y la lúdica, } \\
\text { que redundará en el diseño } \\
\text { de unas orientaciones sobre } \\
\text { la enseñanza de la educación } \\
\begin{array}{l}\text { ambiental dirigida a docentes de } \\
\text { educación inicial. }\end{array}\end{array}$ & $\begin{array}{l}\text { Orientaciones sobre la } \\
\text { enseñanza de la educación } \\
\text { ambiental dirigida a docentes } \\
\text { de educación inicial. }\end{array}$ & $\begin{array}{l}\text { Diseño de unas } \\
\text { orientaciones sobre la } \\
\text { enseñanza de la educación } \\
\text { ambiental dirigida a } \\
\text { docentes de educación } \\
\text { inicial. }\end{array}$ & $\begin{array}{l}\text { Docentes de Jardines } \\
\text { Prescolares. } \\
\text { Estudiantes del programa } \\
\text { Licenciatura en Educación } \\
\text { Preescolar. } \\
\text { Niños en Edades de 4-6 años. }\end{array}$ \\
\cline { 2 - 4 } & $\begin{array}{l}\text { Publicación de artículo en } \\
\text { revista indexada. }\end{array}$ & $\begin{array}{l}\text { Estudiantes del programa } \\
\text { Licenciatura en Educación } \\
\text { Preescolar. }\end{array}$ \\
\hline
\end{tabular}

Fuente: elaboración propia. 
Relacionados con desarrollos tecnológicos e innovación:

Tabla 8. Desarrollo tecnológico e innovación

\begin{tabular}{|c|c|c|c|}
\hline Objetivo de la propuesta & $\begin{array}{c}\text { Resultado/Producto } \\
\text { esperado }\end{array}$ & Indicador & Beneficiario \\
\hline $\begin{array}{c}\text { Analizar los efectos de la } \\
\text { implementación de habilidades } \\
\begin{array}{c}\text { cognitivas a través de la educación } \\
\text { el diseño de unas orientaciones sobre la } \\
\text { enseñanza de la educación ambiental } \\
\text { dirigida a docentes de educación inicial. }\end{array}\end{array}$ & $\begin{array}{c}\text { Orientaciones sobre la } \\
\text { enseñanza de la educación } \\
\text { ambiental dirigida a } \\
\text { docentes de educación } \\
\text { inicial, en medio virtual y en } \\
\text { físico. }\end{array}$ & $\begin{array}{c}\text { Diseño de unas } \\
\text { orientaciones } \\
\text { sobre la enseñanza } \\
\text { de la educación } \\
\text { ambiental dirigida } \\
\text { a docentes de } \\
\text { educación inicial. }\end{array}$ & $\begin{array}{c}\text { Estudiantes del } \\
\text { programa de } \\
\text { Licenciatura en } \\
\text { Educación Infantil. }\end{array}$ \\
\hline
\end{tabular}

Fuente: elaboración propia.

Conducentes al fortalecimiento de la capacidad científica institucional:

Tabla 9. Fortalecimiento de la comunidad científica

\begin{tabular}{|c|c|c|c|}
\hline Objetivo de la propuesta & Resultado/Producto esperado & Indicador & Beneficiario \\
\hline Determinar la importancia de la \\
$\begin{array}{c}\text { educación ambiental y la lúdica } \\
\text { para el fomento de habilidades } \\
\text { cognitivas en niños de 4 a } 6 \text { años } \\
\text { en cuatro jardines infantiles de } \\
\text { Bucaramanga. }\end{array}$ & $\begin{array}{c}\text { Presentación de avances del } \\
\text { proyecto a estudiantes del } \\
\text { programa de Licenciatura en } \\
\text { Educación Infantil. }\end{array}$ & $\begin{array}{c}\text { Inclusión en la Guía } \\
\text { Cátedra. }\end{array}$ & $\begin{array}{c}\text { Estudiantes del } \\
\text { programa de } \\
\text { Licenciatura en } \\
\text { Educación Infantil. }\end{array}$ \\
\cline { 2 - 4 } & $\begin{array}{c}\text { Fortalecimiento del semillero en } \\
\text { educación ambiental }\end{array}$ & $\begin{array}{c}\text { Propuestas de } \\
\text { investigación entrono } \\
\text { a la temática. }\end{array}$ & $\begin{array}{c}\text { Estudiantes } \\
\text { pertenecientes al } \\
\text { semillero. }\end{array}$ \\
\hline
\end{tabular}

Fuente: elaboración propia.

Dirigidos a la apropiación social del conocimiento:

Tabla 10. Apropiación social del conocimiento

\begin{tabular}{|c|c|c|c|}
\hline Objetivo de la propuesta & Resultado/Producto esperado & Indicador & Beneficiario \\
\hline \multirow{3}{*}{$\begin{array}{l}\text { Determinar la importancia de la } \\
\text { educación ambiental y la lúdica } \\
\text { para el fomento de habilidades } \\
\text { cognitivas en niños de } 4 \text { a } 6 \text { años } \\
\text { en cuatro jardines infantiles de } \\
\text { Bucaramanga. }\end{array}$} & Artículo científico. & $\begin{array}{c}\text { Elaboración de } \\
\text { artículo para ser } \\
\text { publicado. }\end{array}$ & $\begin{array}{l}\text { Comunidad } \\
\text { científica. }\end{array}$ \\
\hline & Presentación de ponencia. & $\begin{array}{l}\text { Participación en } \\
\text { evento científico. }\end{array}$ & $\begin{array}{l}\text { Comunidad } \\
\text { científica }\end{array}$ \\
\hline & $\begin{array}{c}\text { Orientaciones sobre la } \\
\text { enseñanza de la educación } \\
\text { ambiental dirigida a docentes } \\
\text { de educación inicial, en medio } \\
\text { virtual y en físico. }\end{array}$ & $\begin{array}{l}\text { Publicación de } \\
\text { las orientaciones } \\
\text { diseñadas. }\end{array}$ & $\begin{array}{l}\text { Docentes y niños de } \\
\text { jardines infantiles. }\end{array}$ \\
\hline
\end{tabular}

Fuente: elaboración propia. 
Impactos esperados a partir del uso de los resultados:

Tabla 11. Impactos esperados:

\begin{tabular}{|c|c|c|c|}
\hline Impacto esperado & $\begin{array}{c}\text { Plazo (años) después de } \\
\text { finalizado el proyecto* }\end{array}$ & Indicador verificable & Supuestos* \\
\hline Educativo & Corto plazo & $\begin{array}{c}\text { Presentación del proyecto a } \\
\text { la comunidad estudiantil del } \\
\text { programa Licenciatura en } \\
\text { Educación Infantil. }\end{array}$ & $\begin{array}{c}\text { Comunidad Educativa que } \\
\text { conoce los alcances del proyecto } \\
\text { y los utiliza como referentes. }\end{array}$ \\
\hline Ambiental y social & Corto plazo & $\begin{array}{c}\text { Uso de las orientaciones } \\
\text { diseñadas sobre la enseñanza de } \\
\text { la educación ambiental. }\end{array}$ & $\begin{array}{c}\text { Docentes de educación inicial } \\
\text { que utilizan las orientaciones } \\
\text { sobre la enseñanza de la } \\
\text { educación ambiental. }\end{array}$ \\
\hline
\end{tabular}

* Plazos: corto (1- 4), mediano (5-9), largo (10 o más).

Fuente: elaboración propia.

\section{Impacto ambiental del proyecto}

El proyecto generó efectos positivos a partir de las actividades a realizar durante su ejecución en la comunidad educativa del programa Licenciatura en Educación Infantil, así como en los dos jardines infantiles objeto de estudio, tanto en docentes como en estudiantes, dado que las orientaciones diseñadas sobre la enseñanza de la educación ambiental podrán ser utilizadas en el aula de clase.

\section{Conclusiones}

El trabajo realizado permitió comprobar que es posible fomentar el desarrollo de habilidades cognitivas en los niños de 4 a 6 años utilizando la lúdica como herramienta pedagógica y el ambiente como el espacio que brinda diversos tipos de recursos para lograrlo. A través de acciones específicas que incluían actividades para desarrollar la atención, la percepción y la memoria, los niños realizaron acciones como la observación, la comparación, la clasificación, la formulación de hipótesis, la experimentación e inferencia, entre otras que los llevaron a encontrar su propio conocimiento y a dar respuesta a las inquietudes generadas durante las actividades.
En la actualidad se vive una crisis ambiental, generada por el impacto de las acciones de los seres humanos en su entorno. El nivel de afectación es tan amplio que no solo está en riesgo un lugar, sino el mundo y todas las especies. Hernández, Ferriz et al. (2010, p. 2) afirman que en los lugares del planeta en donde no hay guerras existen conflictos del hombre consigo mismo y con su ambiente. Muchos son los causantes de esta crisis mundial: entre ellos, las desigualdades sociales, el estilo de vida, el consumismo excesivo, una economía sin regular, que violenta al hombre y los ecosistemas, el abuso en el uso de las energías no renovables y la poca disposición para la investigación y búsquedas de alternativas limpias y renovables. Es por ello, que se apunta a la educación ambiental desde edades tempranas, para promover un aprendizaje que permita a los estudiantes comprender la situación actual y hacer que ellos, de manera individual o colectiva, pueden generar cambios en pro de la conservación de su ambiente y de la solución de problemas actuales o que prevengan algunos que puedan presentarse en el futuro.

En lo relacionado con la lúdica, definida por la Real Academia Española como "todo lo relacionado 
con el juego", y para comprender su significado, de acuerdo con Sanuy, "la palabra juego, proviene del término inglés 'game' que viene de la raíz indo-europea 'ghem' que significa saltar de alegría", hay que brindar "la oportunidad de divertirse y disfrutar al mismo tiempo en que se desarrollan muchas habilidades" (1998, citado en Chacón, 2008, p. 13). Por lo tanto, cada actividad que se proponga utilizando esta estrategia debe buscar no solo la consecución de un objetivo sino el disfrute, mientras se realiza el aprendizaje.

Cuando el juego es reglado, incluye momentos de acción pre reflexiva y de simbolización o apropiación abstracta-lógica de lo vivido para el logro de objetivos de enseñanza curriculares, cuyo objetivo último es la apropiación por parte del jugador de los contenidos y el fomento y desarrollo de la creatividad (Chacón, 2008). Por ello es tan importante el uso de esta estrategia para el desarrollo de habilidades cognitivas, por ser una herramienta útil para alcanzar cualquier tipo de objetivo en las diversas áreas de aprendizaje y por ofrecer experiencias significativas que, en la medida en que sean positivas, dejarán en el estudiante una mayor huella de recordación.

La relación entre juego y aprendizaje es natural; los verbos "jugar" y "aprender" confluyen. Ambos vocablos implican superar obstáculos, encontrar el camino, entrenarse, deducir, inventar, adivinar y llegar a ganar... para pasarla bien, para avanzar y mejorar (Andrés y García, s.f.).

Al realizar juegos se requieren todos los canales sensoriales, pero con frecuencia se enfatiza en la percepción visual y auditiva, las cuales contribuyen al desarrollo de habilidades lógicas que llevan a deducir, analizar, detallar y sacar conclusiones o a estar atentos para culminar con éxito el juego o para ser el ganador de la partida. De esta manera, el docente se aleja del método tradicionalista de ser el que tiene el saber, para ser un moderador y proveedor de situaciones, estrategias, materiales y recursos que generen diversión. Así se les permite a los par- ticipantes ser creadores de su propio conocimiento, sus estrategias y sus recursos y se les alienta a desarrollarlos cumpliendo un objetivo, que no es solo lúdico sino relacional: seguir las normas, respetar los acuerdos y turnos, regular las emociones y controlar las reacciones ante el fracaso o la victoria.

Luego de revisar, seleccionar y analizar las actividades implementadas por las maestras en formación de la Licenciatura de Educación Infantil, es posible resaltar la gran importancia del uso de la lúdica y la educación ambiental en el fomento de habilidades cognitivas en niños de 4 a 6 años de edad en dos jardines infantiles de Bucaramanga. A partir de las habilidades cognitivas seleccionadas para el desarrollo de esta investigación, se analizaron los siguientes hallazgos.

\section{La atención}

Las actividades ejecutadas, en su gran mayoría, utilizaron como estrategia la observación directa, el seguimiento de instrucciones, la observación de videos, el juego de roles, la secuenciación de imágenes, la narración de cuentos e historias, los juegos de seguimiento de instrucciones y la experimentación. Los temas estuvieron relacionados con los ejes temáticos que desarrollaban las instituciones en los momentos en que se implementaron y se seleccionaron las actividades que tenían relación con el medio ambiente o con los elementos que lo conforman.

Retomando el concepto de atención, es definida como la capacidad de seleccionar y concentrarse en los estímulos relevantes, es decir, que el aprendiz pueda seleccionar, de entre todos los estímulos que recibe, aquellos que son relevantes para lo que va a aprender en determinado momento y que, en consecuencia, produzca a partir de este procesamiento mental una respuesta acorde con lo que está atendiendo. La manera dinámica o divertida en que fueron planteadas las actividades permite no solo motivar y captar la atención de los niños, promover interacciones sociales asertivas y favorecer procesos de comunicación claros y precisos que contribuyan 
en la comprensión de lo que se dice o se hace, sino también incrementar el interés en las acciones propuestas, mayor participación espontánea y permanencia en la ejecución de una actividad.

Por lo observado en la implementación y corroborado por los diarios de campo, los participantes tuvieron niveles atencionales acordes con su edad y algunos los superaron, puesto que lograron centrarse y mantenerse atentos durante el tiempo de ejecución de las actividades propuestas; esto permitió la efectividad de las actividades, al lograr el cumplimiento de los objetivos que se plantearon para su realización.

\section{La percepción}

La percepción es el proceso cognitivo que da significado a una sensación física o a un estímulo y produce una interpretación del mundo externo. Sin sensación no hay percepción y sin esta no es posible establecer recuerdos. En la revisión de las actividades fue posible detectar que los dos canales sensoriales más utilizados en las acciones propuestas fueron el auditivo y el visual, a través de los cuales se produce un fenómeno conocido como transducción, que es la transformación de una energía en otra. En el sistema nervioso, la transducción ocurre cuando la energía ambiental se convierte en energía eléctrica. En el caso de lo visual, la información es percibida a través de los ojos, los cuales captan los reflejos que proyectan los objetos que observamos. Estos reflejos son llevados por el nervio óptico hasta la retina, que se encarga de hacer que el cerebro reciba y transforme la energía lumínica y la convierta en energía eléctrica, para que el cerebro la pueda reconocer e interpretar.

El proceso auditivo es similary solamente cambian los canales de recepción de esta información: los sonidos ingresan por el canal auditivo externo hasta llegar a la membrana timpánica, que vibra en respuesta al sonido, unida como está a la cadena de huesecillos que constituyen el oído medio (martillo, yunque, estribo). Aquí el estímulo aéreo se convier- te en mecánico y, al pasar al oído interno, se transforma en impulsos eléctricos, que el cerebro puede interpretar, comprender y dar responder. Existe una memoria sensorial, la cual se encarga de hacer el registro inicial de la información recopilada a través de los diferentes canales sensoriales.

Las actividades ejecutadas utilizaron como estrategias: tecnologías, diversas perspectivas artísticas, resolución de problemas a partir de experimentos, observación, manipulación, comparación y análisis de elementos del entorno, por ejemplo, desde la observación de la semilla, su proceso de germinación, seguimiento al crecimiento, identificación de las partes de la planta y sus posibles usos. Se narraron cuentos, actividades que contribuyeron al desarrollo del vocabulario, debido a la diversidad de palabras, expresiones y frases a las que se expone a los niños, en donde se requiere usar los diferentes canales de recepción de la información para potenciar habilidades de discriminación auditiva. Además, el uso de material lúdico para recrear los cuentos contribuye al uso de diferentes canales de percepción: visual, auditiva, háptica.

Otras actividades estuvieron relacionadas con la ejercitación corporal mediante la imitación del desplazamiento de algunos animales: asociar partes para construir un todo mediante el uso de rompecabezas, actividades promotoras de la creatividad y el reconocimiento de melodías, ritmos y letras de canciones, además de la identificación de sonidos onomatopéyicos relacionados con los animales trabajados. Se realizaron también actividades enfocadas en el cuidado y conservación de los ambientes y para fomentar trabajo colaborativo. Como resultado, se generaron espacios de escucha y respeto por las ideas propias y de los demás, se tomaron decisiones conjuntas y se realizaron aportaciones valiosas al saber, entendido como construcción colectiva que tiene mayor significado y provoca mayor interés en los participantes, porque ven reflejado en este hecho el que se consideren importantes sus opiniones. 
Otros canales sensoriales trabajados fueron el háptico, gustativo y olfativo a través de la realización de recetas, la degustación de los productos elaborados y la manipulación de los materiales usados para su procesamiento.

\section{La memoria}

Existen diferentes definiciones de memoria y todas coinciden en que es la capacidad para adquirir, almacenar, recuperar y utilizar la información. Sin la memoria el ser humano no sería capaz de percibir, aprender o pensar, ni podría expresar las ideas o formarse una identidad personal. Del mismo modo, sería imposible que el ser humano conociera y comprendiera el mundo que lo rodea, ni que resolviera los problemas presentes en él. Portellano establece que "la memoria es una función neurocognitiva que permite registrar, codificar, consolidar, retener, almacenar, recuperar y evocar la información previamente almacenada" (2005, p. 227), es decir, es la capacidad de retener la información aprendida.

El cuento se constituye en un recurso importante como estrategia para acercar a los niños al conocimiento natural y fue utilizado de varias maneras, entre las cuales se destacan: la evocación de los conocimientos previos para relacionarlos con los conceptos nuevos obtenidos de la historias narradas o vistas; la organización de secuencias escuchadas; la comparación de las experiencias vividas por los personajes con las propias; el relacionar imágenes con palabras; la realización de representaciones de los relatos, que incluían argumentos tomados de las historias o algunos propios ligados a los eventos ocurridos.

Otra actividad de uso frecuente fueron los juegos de memoria para encontrar parejas en donde debían retener tanto la imagen como el lugar en donde esta se encontraba. Estos juegos favorecen el desarrollo de procesos cognitivos básicos: percepción, atención y memoria. La atención les ayuda a centrarse y mantenerse atentos a la actividad que realizan eliminando los estímulos externos y fortalece el establecimiento de acuerdos y su cumpli- miento para incrementar el nivel de tolerancia a la frustración. En cuanto a la percepción, permite detallar el contenido de las imágenes que se van a parear y su ubicación, cuando estas sean descubiertas. En lo relacionado con la memoria, fomenta el desarrollo del lenguaje oral, ya que les permite utilizar vocabulario nuevo con relación al conjunto de imágenes que están utilizando, además de establecer y retener la relación imagen y el espacio físico donde se encuentran. También se realizaron actividades como juegos de secuencias auditivas, para recordar los elementos en el orden dado por la canción y reconocer algunos sonidos y su procedencia, por ejemplo, de moto, de carro, de ambulancia y de animales.

El conjunto de estas actividades permite verificar la comprensión del tema y su capacidad de memorizar lo escuchado. Según Carlson:

Analizar la historia de un cuento [se ve que este] puede incentivar a los niños a crear una conexión entre sus experiencias personales y las de los personajes. Al identificarse con los personajes del cuento los niños reconocen que no son los únicos que experimentan estos sentimientos o problemas. A través de los temas, personajes e historias presentados en la literatura infantil, los niños pueden aprender estrategias y destrezas que les permitan ser más eficientes e independientes al resolver conflictos. (2001, citado en Castillo, 2013, p. 17)

Al respecto, de acuerdo con el MEN (2014c):

Saber que todo ser humano se nutre de palabras y simbolos y que inventa su historia en esa conversación permanente con las historias de los demás confiere al lenguaje un papel fundamental en la configuración del ser humano. Desde este punto de vista, el lenguaje, en el sentido amplio de capacidad de comunicación y simbolización, [está vinculado con] la lengua -oral y escrita. (p. 4o) 
Se realizaron también actividades con títeres y otras donde se trabajó el esquema corporal, se reflexionó sobre el cuidado y respeto del cuerpo propio y de los demás, mediante el uso de canciones, rondas, juegos musicales, relación de causa y efecto, análisis del ciclo del agua y de los cambios de la materia, mediante el uso de experiencias sensoriales y de experimentación, establecimiento de semejanzas y diferencias entre elementos trabajados, reconocimiento de la importancia del reciclaje y la necesidad de clasificar adecuadamente los residuos, reflexión sobre los cuidados del entorno y el ambiente en general, como promotores de ese cambio.

\section{Referencias}

Andrés, M. y García, M. (s.f.). Actividades lúdicas en la enseñanza de LFE: el juego didáctico. [Documento web]. http://cvc.cervantes.es/obref/ciefe/pdf/o1/cvc_ciefe_01_o016.pdf

Betina Lacunza, A., Contini de González, N. y Castro Solano, A. (2010). Las habilidades cognitivas en niños preescolares. Un estudio comparativo en contexto de pobreza. Acta Colombiana de Psicología, 13(1), 25-34. http:// www.redalyc.org/articulo.oa?id=79815637002

Burshan, S. (2006). Seminario Introducción a la propuesta Educativa Reggio Emilia, Italia. "Una mirada reflexiva hacia la cultura de la infancia", Bogotá, 6 y 7 octubre. http://equidadparalainfancia.org/wp-content/ uploads/2006/og/La-propuesta-educativa-Reggio-Emilia.-Una-mirada-reflexiva-hacia-la-cultura-de-lainfancia..pdf

Campo Ternera, L. A. (2009). Características del desarrollo cognitivo y del lenguaje en niños en edad preescolar. Psicogente, 12(22), 341-351. http://www.redalyc.org/pdf/4975/497552354007.pdf

Castillo, R. (2013). El rol de la literatura en el aprendizaje y el desarrollo de niños y adolescentes. En Biblioteca Digital Scribd 19. https://es.scribd.com/document/376092362/el-rol-de-la-literatura-en-el-aprendizaje-ydesarrollo-de-ninos-y-adolescentes-pdf

Carlson, S. M. y Moses, L. J. (2001). Individual differences in inhibitory control and children's theory of mind. Child Development, 72, 1032-1053. https://doi.org/10.1111/1467-8624.00333

Chacón, P. (2008). El juego didáctico como estrategia de enseñanza y aprendizaje ¿Cómo crearlo en el aula? [Documento web]. http://www.e-historia.cl/cursosudla/13-EDU413/lecturas/06\%20-\%20El\%20Juego\%20 Didactico\%20Como\%20Estrategia\%2Ode\%20Ense\%C3\%B1anza\%20y\%2OAprendizaje.pdf

Díaz, E. (2016). Implementación de estrategias metacognitivas para un aprendizaje significativo. Tesis de Maestría en Educación, Instituto Tecnológico de Monterrey. https://repositorio.tec.mx/bitstream/ handle/11285/622492/O2Ernesto\%20D\%c3\%adaz\%2oEsteves.pdf?sequence=1\&isAllowed=y

Elliot, J. (2000). La investigacción acción. Morata.

Elosúa, M. y García, E. (1993). Estrategias para enseñar y aprender a pensar (caps. 1-4) Narcea. http://www.cucs. udg.mx/avisos/Martha_Pacheco/Software\%20e\%20hipertexto/Antologia_Electronica_pa121/ELOSUA.PDF 
Farkas, K., Grothusen, B., Muñoz, B. y Von Freeden, S. (2006). Revisión de las habilidades socio-cognitivas en la infancia temprana. Revision of Social-cognitive Skills in early childhood Chamarrita. Summa Psicológica, 3(1), 31-34. https://dialnet.unirioja.es/servlet/articulo?codigo $=4808678$

Figueroa, B. J. (2015). El desarrollo de las habilidades cognitivas a través de la enseñanza de las plásticas y visuales. Tesis de Licenciatura en Artes Plásticas y Visuales, Universidad Santo Tomás, Bogotá. https://repository. usta.edu.co/bitstream/handle/11634/3104/Figueroajames2015.pdf?sequence=1\&isAllowed=y

Fuenmayor, G. y Villamil, Y. (2008). La percepción, la atención y la memoria como procesos cognitivos utilizados para la comprensión. Revista de Artes y Humanidades Unica, 9(22), 187-202. http://www.redalyc.org/articulo.oa?id=170118859011

Gámez, N. (2019). Implementación de estrategias metacognitivas para el aprendizaje significativo en el nivel inicial. Tesis de Maestría en Innovación en Educación, Pontifica Universidad Católica del Ecuador. https:// repositorio.pucese.edu.ec/bitstream/123456789/1986/1/G\%C3\%81MEZ\%2OTOLOZA\%2ONIDIA\%2OMAYANEY\%2O.pdf

García, J (1.997). Psicología de la atención. Síntesis Psicología.

Hernández, A., Ferriz, Á., Herrero, Y., González, L., Morán, C., Brasero, A. y Ortega, A. M. (2010). La crisis ecosocial en clave educativa. Una guía didáctica para una cultura de paz. Fuhem. https://www.fuhem.es/media/ ecosocial/file/Proyecto\%2oDimensiones\%20de\%20la\%2opaz/Guia\%2oecosocial/GUIA_ECOSOCIAL_texto_completo.pdf

Hernández, S. R., Fernández, C. C. y Baptista, L. M. (2010). Metodología de la investigación (5 ed.). McGraw-Hill.

Inspirados en Reggio Emilia (s.f.). Reggio Emilia y la pedagogia de la escucha. [Blog]. http://www.inspiradosenreggioemilia.com/reggio-emilia-y-la-pedagogia-de-la-escucha/

Lacunza, A., Contini, N. y Castro, A. (2010). Las habilidades cognitivas en niños preescolares. Un estudio comparativo en un contexto de pobreza. Acta Colombiana de Psicología, 13(1). http://www.scielo.org.co/scielo. php?script=sci_arttext\&pid=S0123-91552010000100003

Lavado, P., Aragón, C. y Gonzales, M. (2015). ¿Cuál es la relación entre las habilidades cognitivas y no cognitivas y la adopción de comportamientos de riesgo? Un estudio para el Perú. Apuntes, 42(76), 59-93. https://doi. org/10.21678/apuntes.76.729

Lewin, K. (1946). La investigación acción participativa. OEI.

López, V. (2007). Social intelligence: Contributions from its study in children and adolescents with high cognitive abilities. Psyke, 16(2), 17-28. http://dx.doi.org/10.4067/S0718-22282007000200002

Millá, M. (2006). Atención temprana de las dificultades de aprendizaje. Revista de Neurología, 42(suplemento), 153156. http://www.mdp.edu.ar/psicologia/psico/sec-academica/asignaturas/aprendizaje/Materiales_2014/ TAAtencion_temprana_de_las_dificultades_aprendizaje.pdf 
Ministerio de Educación Nacional - MEN (2014a). Documento No. 22. El juego en Educación inicial. Serie de orientaciones pedagógicas para la educación inicial en el marco de la atención integral. Rey Naranjo Editores.

Ministerio de Educación Nacional - MEN (2014b). Documento No. 24. La exploración del medio en la educación inicial. Serie de orientaciones pedagógicas para la educación inicial en el marco de la atención integral. Rey Naranjo Editores.

Ministerio de Educación Nacional - MEN (2014c). Documento No. 23. La literatura en la educación inicial. Serie de orientaciones pedagógicas para la educación inicial en el marco de la atención integral. Rey Naranjo Editores.

Montoya, D. M., Varela, V. y Dussan-Lubert, C. (2012). Correlation between the reading and writing academic skills and the neuropsychological performance in a sample of children with adhd from the city of Manizales. Psicología desde el Caribe, 29(2), 305-329. https://www.researchgate.net/publication/262463642_Correlation_between_the_reading_and_writing_academic_skills_and_the_neuropsychological_performance_in_a_sample_of_children_with_adhd_from_the_city_of_manizales

Piaget, J. (2005). Inteligencia y afectividad. Prólogo de Mario Carretero. Aique.

Portellano, J. (2005). Introducción a la neuropsicología. McGraw-Hill.

Portellano, J. y García, J. (2014). Neuropsicología de la atención, funciones ejecutivas y la memoria. Síntesis.

Revista 21 (s.f.). Los últimos descubrimientos sobre el desarrollo de la mente en la infancia. [Reseña de la obra de A. Gopnik, El filósofo entre pañales] https://www.21rs.es/es/noticias/1191_Los-ultimos-descubrimientossobre-el-desarrollo-de-la-mente-en-la-infancia.html

Romero, Y. y Tapia, F. (2014). Desarrollo de las habilidades cognitivas en niños de edad escolar. Multiciencia, 14(3), 297-303. https://www.redalyc.org/articulo.oa?id=90432809008

Sáiz, M. M., Carbonero, M. y Román, S. J. (2014). Aprendizaje de habilidades de autorregulación en niños de 5 a 7 años. Universitas Psychologica, 13(1). https://doi.org/10.11144/Javeriana.UPSY13-1.ahan

Santana, Y. y Ortega, R. (2010). Orientaciones sobre educación ambiental para los profesores de formación de la enseñanza media superior. Delos. Desarrollo Local Sostenible, 3(8), 1-12. http://www.eumed.net/rev/delos/o8/seov.htm

Sierra B., S. C. (2017). Experimentos cientificos infantiles como medios para generar actitudes y aptitudes investigativas en los niños de 5 años del grado transición del colegio Liceo Pedagógico la Dicha del Saber de la ciudad de Bucaramanga. Tesis de Licenciatura en Educación Preescolar, Universidad Santo Tomás, Bucaramanga. 1-145. https://repository.usta.edu.co/handle/11634/10776

Tortolero, B. (s.f.). La atención como proceso activo del aprendizaje. Psicopedia.org. https://psicopedia.org/7179/ atencion-proceso-activo-del-aprendizaje/

Varela, F. J. (1998). Conocer. Gedisa. 